Journal of Molecular Catalysis A: Chemical 367 (2013) 77-88.

http://dx.doi.org/10.1016/j.molcata.2012.09.030

\title{
n-Heptane hydroconversion over nickel-loaded aluminum- and/or boron- containing BEA zeolites prepared by recrystallization of magadiite varieties
}

\author{
R.M. Mihályi a , F. Lónyi a , H.K. Beyer ${ }^{\text {b }}$, Á. Szegedi a, M. Kollár ${ }^{\text {a }}$, G. Pál-Borbély a , J. Valyon a \\ ${ }^{a}$ Institute of Materials and Environmental Chemistry, Research Centre for Natural Sciences, Hungarian \\ Academy of Sciences, Pusztaszeri u. 59-67, Budapest H-1025, Hungary \\ ${ }^{b}$ Research and Development for Silicates and Ceramics Ltd, Gránátos u. 4, Budapest H-1106, Hungary
}

\begin{abstract}
Phase-pure [Al]BEA and [A1,B]BEA zeolites, prepared by solid-state recrystallization of synthetic aluminum-containing magadiites and conventionally synthesized [B]BEA, were tested, after ion exchange with nickel, as bifunctional catalysts for hydroconversion of $n$-heptane. The reducibility of nickel ions incorporated into BEA zeolites by ion exchange was investigated by temperature-programmed reduction (TPR). The acidity of the samples was characterized with strong (pyridine (Py), ammonia $\left(\mathrm{NH}_{3}\right)$ ) and weak (nitrogen) bases. The adsorbed bases were studied by transmission FT-IR (Py), diffuse reflectance infrared Fourier-transform (DRIFT) spectroscopy $\left(\mathrm{N}_{2}\right)$, and temperatureprogrammed ammonia evolution (TPAE, $\mathrm{NH}_{3}$ ). Over $\mathrm{Ni} / \mathrm{H}-[\mathrm{B}] \mathrm{BEA}$ the reactants were completely converted via fast hydrogenolysis, whereas this reaction pathway plays only a negligible role in the hydroconversion over $\mathrm{Ni} / \mathrm{H}-[\mathrm{Al}] \mathrm{BEA}$ and $\mathrm{Ni} / \mathrm{H}-[\mathrm{Al}, \mathrm{B}] \mathrm{BEA}$ zeolites. Boron-containing BEA zeolites were less active catalysts than the boron-free catalyst in the principal unimolecular hydroconversion reactions. However, incorporation of boron into the framework of BEA zeolite results in a considerable selectivity shift towards isomerization. Results suggest that the acid strength of bridged hydroxyls, probed with weak $\left(\mathrm{N}_{2}\right)$ and strong basis (pyridine), was found to be similar in the boron-free and boroncontaining BEA samples. The decrease in the isomerization rate and the increase of the apparent activation energy upon incorporation of boron may be attributed to the decrease in the heat of $n$-heptane adsorption.
\end{abstract}

Keywords: [A1,B]BEA-type zeolites; Acidity; Adsorption heat; Bifunctional Ni/H-BEA; nHeptane hydroconversion

\section{Introduction}

Hydroconversion reactions of alkanes over bifunctional $\mathrm{Pt} / \mathrm{H}$-zeolite catalysts have been extensively studied since the 70ties of the last century [1-7]. The path and mechanism of the involved reactions, the nature and mode of action of the diverse catalytically active sites in the individual catalyst components, the role of the chain length of the paraffinic reactants and reaction conditions, and the significance of the crystal structure of the zeolite applied as acidic component of the catalyst have been studied in detail. In the last decade, however, mesoporous molecular sieves, such as MCM-41 [8-10] were also investigated in the hydroconversion of $n$-paraffins.

Several processes using bifunctional zeolite catalysts were upgraded to the industrial scale 
for, e.g., improvement of the octane number of gasoline fractions by hydroisomerization or dewaxing of gas oils by concerted hydrocracking and hydroisomerization. Industrial hydroisomerization were developed for $\mathrm{C}_{5} / \mathrm{C}_{6}$ paraffins using $\mathrm{Pt} / \mathrm{H}$-mordenite catalysts [11], but no process exists for $\mathrm{C} 7$ paraffin because of its higher tendency to be cracked. It is a challenge to find catalysts favoring the isomerization of n-heptane into high octane number multibranched isomers without too much cracking.

With the discovering of zeolite BEA at the end of the eighties this zeolite with threedimensional interconnected 12-membered ring channels has held particular interest as acidic catalyst in the field of hydroconversion of alkanes. $\mathrm{Pt} / \mathrm{H}-\mathrm{BEA}$ was found to be much more active and selective to isomerization in n-heptane hydroisomerization than $\mathrm{Pt} / \mathrm{H}$ mordenite. This effect can be explained by the shorter residence time of the $\mathrm{i}-\mathrm{C} 7^{+}$ intermediate in the three-dimensional 12-MR channels and large intersections of beta zeolite than that in the unidimensional 12-MR channels of mordenite $[12,13]$.

Comparing to other zeolites $\mathrm{Pt} / \mathrm{H}-\mathrm{BEA}$ is considered to be a promising catalyst for hydroisomerization of $\mathrm{n}-\mathrm{C} 7$ [14]. Most of the relevant studies concern bifunctional catalysts with noble metals (Pt,Pd) as hydrogenation component, e.g. [6,7]. In contrast, only a few studies [14-17], deal with the catalytic behavior of $\mathrm{Ni} / \mathrm{H}-\mathrm{BEA}$. The isomerization/crack selectivity of these catalysts is known to depend crucially on the acid site density, the acid strength of the sites and the metal/acid ratio. Dealumination of BEA by $\mathrm{HCl}$ acid leaching results in a significant in the yield of heptane isomers [18]. However, it is not known yet, whether the selectivity can be, in principle, also controlled (and eventually to which extent) by substitution of boron for aluminum in the framework of BEA zeolite.

Very recently [19] the dry-state crystallization technique has been adapted to the synthesis of [Al]BEA and phase-pure [A1,B]BEA variants by recrystallization of synthetic aluminum-containing magadiite with TEAOH as template in the absence and presence of sodium tetraborate $\left(\mathrm{Na}_{2} \mathrm{~B}_{4} \mathrm{O}_{7}\right)$, respectively. It was shown that during recrystallization of layered silicate not only aluminum but boron are also incorporated into the beta zeolite framework. The main advantage of the method is that the Brønsted acid sites of the beta zeolite samples can be controlled by varying the Al content of the layered silicate and the borax content. In the present paper thus-prepared materials already characterized in [17] by various chemical-physical techniques were applied, after introduction of nickel ions by ion exchange, as catalysts for the hydroconversion of heptane. The study focuses on effects of partial substitution of boron for framework aluminum in BEA zeolite (i) on the intrinsic acid strength of bridged hydroxyls associated with tetrahedrally coordinated aluminum, (ii) on the ion exchange capacity and site occupation by nickel ions, (iii) on the reducibility of the incorporated nickel ions, and (iv) on catalytic activity and selectivity of bifunctional catalysts containing such variants of zeolite BEA as acidic component. Considering economic aspects and current trends in relevant petrochemical processes, the present study aims at nickel-containing bifunctional catalysts with enhanced isomerization selectivity.

\section{Experimental}

\subsection{Materials}

Phase-pure [B]BEA, [Al]BEA and three [Al,B]BEA zeolite samples with different Al and boron contents (designated as [A1,B]BEA-I, [A1,B]BEA-II and [A1,B]BEA-III) were synthesized according to methods described in our previous paper [19]. Ammonium or sodium forms of the zeolite samples were prepared by repeated ion exchange with $0.5 \mathrm{M}$ ammonium or sodium chloride solutions $(25 \mathrm{ml} / \mathrm{g})$, $\mathrm{pH}$ value of 7.5-8 was adjusted with ammonia and $\mathrm{NaOH}$ solution, respectively. Subsequently, nickel ions were incorporated into the $\mathrm{Na}$ - and $\mathrm{NH}_{4}$-zeolites by ion exchange with 0.08 molar nickel acetate solution at 
room temperature or $340 \mathrm{~K}$ for $5 \mathrm{~h}$. Then the samples were washed with water, and dried at about $353 \mathrm{~K}$. The chemical compositions of the prepared samples are listed in Table 1.

In order to reduce the number of Brønsted-acid sites of the $\mathrm{Ni}$, Na-[Al]BEA sample the catalyst was stirred in $0.1 \mathrm{~N} \mathrm{NaOH}$ solution at room temperature for $0.5 \mathrm{~h}$ (sample designated as Ni,Na-[Al]BEA-p).

\subsection{Methods}

Aluminum, sodium and nickel were determined by atomic absorption spectroscopy (AAS) after digestion of the samples with hydrofluoric acid. B was measured after extraction from the samples with 1 molar $\mathrm{HCl}$ solution at $373 \mathrm{~K}$ by induced coupled plasma (ICP) at $249.77 \mathrm{~nm}$. The silica content was assumed to equal the mass of the bulk minus the sum of $\mathrm{Na}_{2} \mathrm{O}, \mathrm{Al}_{2} \mathrm{O}_{3}, \mathrm{~B}_{2} \mathrm{O}_{3}$ and $\mathrm{NiO}$. The ammonium ion content was determined by titration of the ammonia evolved during temperature-programmed heating up to $873 \mathrm{~K}$.

X-ray diffractograms were measured with a Philips PW1810/1870 diffractometer (graphite monochromator, $\mathrm{Cu}-\mathrm{K}_{\alpha}$ radiation) before and after in situ reduction with hydrogen at $723 \mathrm{~K}$. The standard-related integrated intensity of the [302] reflections of zeolite BEA at $2 \theta=22.5^{\circ}$ was considered as measure of the so-called "X-ray crystallinity". Profile fitting was applied for the deconvolution of overlapping zeolite and nickel reflections. The average particle size of metallic nickel particles was estimated of the full width at half maximum (FWHM) values of [111] and [200] reflections at $2 \theta=44.5^{\circ}$ and $51.8^{\circ}$, respectively, according to the Scherrer equation.

Transmission electron micrographs were obtained with a Philips CM10 electron microscope.

IR transmission spectra were recorded with a Nicolet FT-IR spectrometer (Impact 400) before and after adsorption of pyridine as probe molecule using the wafer transmission technique. Sample treatment at $723 \mathrm{~K}$ in high vacuum $\left(10^{-6} \mathrm{mbar}\right)$, reduction of nickel ionexchanged samples with hydrogen at $723 \mathrm{~K}$ and loading with pyridine at $473 \mathrm{~K}$ and 5.7 mbar for $30 \mathrm{~min}$ as well as subsequent degassing of the pyridine-loaded samples in high vacuum at $373 \mathrm{~K}$ were performed in situ in an IR cell identical with that described by Karge and Niessen [20].

Diffuse reflectance infrared Fourier transform (DRIFT) spectra were obtained with a Nicolet 5PC FT-IR spectrometer equipped with MCT type detector, a COLLECTOR ${ }^{\mathrm{TM}}$ II diffuse reflectance mirror system and a high-temperature/high-pressure cell (SpectraTECH Inc.). Dehydration and deammoniation of the finely powdered samples applied in the ammonium form were performed in situ in the DRIFT cell by heating in a $10 \% \mathrm{O}_{2} / \mathrm{He}$ gas flow up to $773 \mathrm{~K}$ (heating rate $10 \mathrm{~K} \mathrm{~min}^{-1}$ ) and tempering for $1 \mathrm{~h}$, followed by a $10 \mathrm{~min}$ flushing period in $\mathrm{He}$ at $773 \mathrm{~K}$. Reflectance IR spectra were collected at $298 \mathrm{~K}$ in flowing helium and at a pressure of 9 bar in nitrogen $\left(50 \mathrm{ml} \mathrm{min}^{-1}\right)$.

Adsorption isotherms of n-heptane were measured with a tapered element oscillating microbalance (TEOM 1500 Pulse Mass Analyzer from Rupprecht \& Patashnick Co.) at temperatures between 423 and $463 \mathrm{~K}$.

TPR of nickel-exchanged zeolites were carried out, subsequent to in situ pretreatment in a flow $\left(20 \mathrm{ml} \mathrm{min}^{-1}\right)$ of $\mathrm{N}_{2}$ or $\mathrm{O}_{2} / \mathrm{He}(20: 80)$, in $\mathrm{H}_{2} / \mathrm{Ar}$ (10:90) using a TPR apparatus equipped with a heat-conductivity cell and a trap for removal of water.

The catalytic experiments were carried out at 5 bar total pressure in a down-stream fixed-bed microreactor (12 mm ID) filled with $1 \mathrm{~g}$ of binder-free catalyst grains prepared by compression of the zeolite powder, crashing and sieving $(0.315-0.63 \mathrm{~mm})$. The nickel ions were reduced at $723 \mathrm{~K}$ in a flow of $\mathrm{H}_{2}\left(150 \mathrm{~N}-\mathrm{ml} \mathrm{min}^{-1}\right)$ for $2 \mathrm{~h}$. n-Heptane was fed into the reactor by a micropump (Pharmacia LKB-Pump P-500). The $\mathrm{H}_{2} / \mathrm{C} 7$ molar ratio amounted to 19.6. The reaction products were analyzed by on-line GC with a FID detector 
and Petrocol DH 50.2 fused silica capillary column. The reaction rates (molar flow rate * conversion / weight of catalyst) were measured at conversion close to $10 \mathrm{wt}$. $\%$.

\section{Results and discussion}

The chemical composition of the Na-, $\mathrm{NH}_{4}^{+}$- and Ni-form of the [B]BEA, [Al]BEA and three $[\mathrm{A} 1, \mathrm{~B}] \mathrm{BEA}$ zeolite samples are shown in Table1. It can be seen that in the series of aluminum- and boron-containing beta samples ([A1,B]BEA-I, [A1,B]BEA-II and [Al,B]BEA-III) the Al-content are decreasing from 1.12 to $0.71 \mathrm{mmol} / \mathrm{g}$, whereas the boron content are increasing from 0.33 to $0.69 \mathrm{mmol} / \mathrm{g}$.

Table 1 Chemical composition of the Beta samples

\begin{tabular}{|c|c|c|c|c|c|c|}
\hline \multirow[t]{2}{*}{ Sample } & \multicolumn{5}{|c|}{ Chemical composition $\left(\mathrm{mmol} \mathrm{g}^{-1}\right)^{3)}$} & \multirow{2}{*}{$\begin{array}{l}\mathrm{Si} / \mathrm{Al} \\
\text { bulk }\end{array}$} \\
\hline & $\mathrm{NH}_{4}$ & $\mathrm{Na}$ & $\mathrm{Ni}$ & $\mathrm{Al}$ & $\mathrm{B}$ & \\
\hline $\mathrm{Na}-[\mathrm{B}] \mathrm{BEA}$ & - & 0.96 & - & 0.05 & 0.70 & 315 \\
\hline $\mathrm{Ni}-[\mathrm{B}] \mathrm{BEA}$ & - & 0.03 & 0.47 & 0.05 & 0.68 & \\
\hline $\mathrm{NH}_{4}-[\mathrm{Al}] \mathrm{BEA}$ & 1.04 & 0.08 & - & 1.16 & - & 13.5 \\
\hline $\mathrm{Na}-[\mathrm{Al}] \mathrm{BEA}$ & - & 0.98 & - & 1.11 & - & 13.7 \\
\hline Ni,Na-[Al]BEA & - & 0.14 & 0.57 & 1.15 & - & 13.0 \\
\hline Ni,Na-[Al]BEA-p ${ }^{1)}$ & - & 0.30 & 0.56 & 1.10 & - & 13.5 \\
\hline $\mathrm{NH}_{4}-[\mathrm{Al}, \mathrm{B}] \mathrm{BEA}-\mathrm{I}$ & 1.21 & 0.02 & - & 0.88 & 0.33 & 17.8 \\
\hline $\mathrm{Ni}, \mathrm{NH}_{4}-[\mathrm{Al}, \mathrm{B}] \mathrm{BEA}-\mathrm{I}$ & 0.16 & 0.01 & 0.46 & 0.90 & 0.29 & 16.8 \\
\hline Na-[Al,B]BEA-I & - & 1.18 & - & 0.89 & 0.28 & 16.9 \\
\hline Ni,Na-[Al,B]BEA-I & - & 0.35 & 0.50 & 0.89 & 0.28 & 16.8 \\
\hline $\mathrm{Ni}, \mathrm{Na}-[\mathrm{Al}, \mathrm{B}] \mathrm{BEA}-\mathrm{I}^{*}{ }^{2)}$ & - & 0.42 & 0.54 & 0.87 & 0.33 & 17.0 \\
\hline $\mathrm{NH}_{4}-[\mathrm{Al}, \mathrm{B}] \mathrm{BEA}-\mathrm{II}$ & 0.99 & 0.23 & - & 0.71 & 0.61 & 21.9 \\
\hline $\mathrm{Ni}, \mathrm{NH}_{4}-[\mathrm{Al}, \mathrm{B}] \mathrm{BEA}-\mathrm{II}$ & - & 0.20 & 0.30 & 0.70 & 0.51 & 21.9 \\
\hline Na-[A1,B]BEA-II & - & 1.11 & - & 0.70 & 0.48 & 21.8 \\
\hline Ni,Na-[Al,B]BEA-II & - & 0.44 & 0.45 & 0.70 & - & \\
\hline $\mathrm{NH}_{4}-[\mathrm{Al}, \mathrm{B}] \mathrm{BEA}-\mathrm{III}$ & 1.06 & 0.22 & - & 0.41 & 0.65 & 38.4 \\
\hline $\mathrm{Ni}, \mathrm{NH}_{4}-[\mathrm{Al}, \mathrm{B}] \mathrm{BEA}-\mathrm{III}$ & - & 0.11 & 0.47 & 0.40 & 0.69 & 38.1 \\
\hline
\end{tabular}

\footnotetext{
1) $\mathrm{Ni}, \mathrm{Na}$-[Al]BEA sample was subsequently ion-exchanged with $0.1 \mathrm{~N} \mathrm{NaOH}$ solution

2) repeated preparation of Ni,Na-[Al,B]BEA-I

3) data are related to $1 \mathrm{~g}$ zeolites calcined at $1273 \mathrm{~K}$
} 


\subsection{Acidity of parent BEA zeolites}

The shift of hydroxyl stretching bands in spectra of acidic zeolite samples upon adsorption of nitrogen at elevated pressures proved to be a phenomenon appropriate for the characterization of interactions between the non-protonating basic probe molecule and structural OH-groups, i.e. for the estimation of the so-called "intrinsic" acidity $[21,22]$.

Fig. 1,A represents diffuse reflectance infrared Fourier-transform (DRIFT) spectra of the H-form of [Al]BEA (a), [A1,B]BEA-I (b) and [A1,B]BEA-III (c) measured in He (full line) and $\mathrm{N}_{2}$ at 9 bar (dashed line). In He the zeolite exhibited bands at wavenumbers practically identical with those in the respective transmission spectra presented in [19]. Adsorption of $\mathrm{N}_{2}$ at 9 bar resulted in a more or less pronounced erosion of the original bands and in a concomitant appearance of new bands at lower wavenumbers. These spectral changes, being more in evidence in the difference spectra (Fig. 1B), are typical of hydrogen-bonding interactions between hydroxyl groups and non-protonating basic molecules like $\mathrm{N}_{2}$. Especially part of the band at $3611 \mathrm{~cm}^{-1}$ attributed to acidic bridged hydroxyls was significantly shifted to lower wavenumbers and appeared as a broad absorption zone centered at $3523 \mathrm{~cm}^{-1}$ assigned to the $v_{\mathrm{OH}}$ vibration of the $\mathrm{OH}_{\text {bridged }} \cdots \mathrm{N}_{2}$ adsorption complex. This $\Delta v_{\mathrm{OH}}$ shift of $88 \mathrm{~cm}^{-1}$ was found for all BEA zeolites independently from their framework boron contents. Since $\Delta v_{\mathrm{OH}}$ reflects the deprotonation energy of the $\mathrm{OH}$ group [16], it can be concluded that in BEA zeolites bridged hydroxyls associated with $\mathrm{Al}(\mathrm{OSi})_{4}$ units are, independently of co-existing framework boron, of the same intrinsic acid strength. The intrinsic acid strength was also not affected by incorporation of sodium cations by ion exchange up to exchange levels of 50-60\% (spectra are not shown).

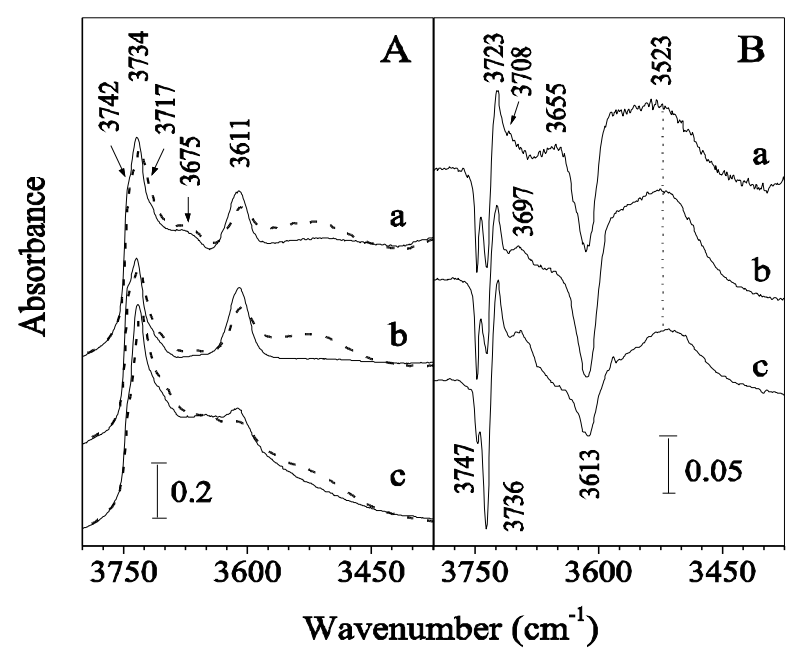

Fig. 1. DRIFT spectra (A) of H-[Al]BEA (a), H-[Al,B]BEA-I (b) and H-[Al,B]BEA-III (c) measured at $298 \mathrm{~K}$ in flowing He (full line) and nitrogen at 9 bar (dashed line) and (B) the respective difference spectra.

The difference spectra of boron-containing BEA zeolites exhibited a positive band at $3697 \mathrm{~cm}^{-1}$ which may be considered as the shifted component of the band at $3734 \mathrm{~cm}^{-1}$. Hence, the $\Delta v_{\mathrm{OH}}$ shift of $37 \mathrm{~cm}^{-1}$ is an evidence for the acidic character of silanol groups associated with tetragonally coordinated framework boron. The acid strength of these $\mathrm{OH}$ groups is naturally much weaker than that of bridged hydroxyls associated with tetrahedral 
framework aluminum. The wavenumbers of very weak or non-acidic silanol groups are even less influenced by adsorbed $\mathrm{N}_{2}$ (shifted by only $15-20 \mathrm{~cm}^{-1}$ ), so that the bands at 3723 and $3708 \mathrm{~cm}^{-1}$ in the difference spectra are irrelevant from the point of view of acidity.

Ammonia TPD curves of $\mathrm{NH}_{4}-[\mathrm{B}] \mathrm{BEA}$ and $\mathrm{NH}_{4}$-[Al]BEA were found to differ typically from each other [19]. Whereas the latter was deammoniated over a broad temperature range between 523 and $873 \mathrm{~K}$, ammonia was completely released from the boron variety already between 423 and $503 \mathrm{~K}$. TPD curves of $\mathrm{NH}_{4}$-[A1,B]BEA zeolites exhibited both the low- and high-temperature evolution step; the amount of $\mathrm{NH}_{3}$ released in the two steps satisfactorily corresponded to the respective boron and aluminum contents. Thus, in line with the results obtained by DRIFT and FT-IR spectroscopy it can be concluded that coexisting framework boron do not influence the acid strength of bridged hydroxyls associated with $\mathrm{Al}(\mathrm{OSi})_{4}^{-}$units. Interestingly, the aluminum-rich $\left.\mathrm{NH}_{4}^{-}-\mathrm{Al}, \mathrm{B}\right] \mathrm{BEA}-\mathrm{I}$ exhibited a deviating ammonia desorption feature inasmuch as the low-temperature evolution step was shifted to significantly higher temperatures. This phenomenon points to an increase of the acid strength of sites associated with framework boron and, hence, to a synergetic effect of coexisting framework aluminum. However, this effect becomes manifest only at high Al/B framework ratio.

\subsection{Characterization of Ni-exchanged BEA zeolites}

\subsubsection{X-ray diffractometry and transmission electron microscopy}

Neither introduction of nickel ions into the prepared BEA varieties by conventional ion exchange nor subsequent reduction of thus-incorporated nickel ions affected the X-ray crystallinity of the zeolitic phase as illustrated by the respective diffractograms of [A1,B]BEA-I in Fig. 2A. Disregarding the aluminum-free [B]BEA, the prepared BEA varieties exchanged with nickel exhibited, after in-situ reduction at $723 \mathrm{~K}$ for 2 hours, Xray diffraction patterns with superimposed patterns of the zeolite and metallic nickel (cf. diffraction patterns $b$ and $c$ in Fig. 2,B).

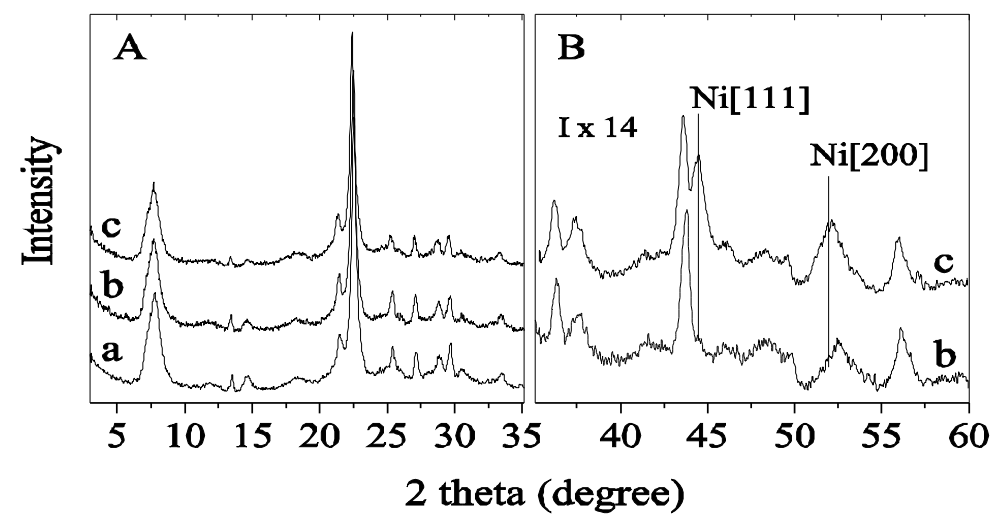

Fig. 2. X-ray diffraction patterns of Na-[Al,B]BEA-I before (a) and after (b) ion exchange with nickel and sample (b) reduced in situ with hydrogen at $723 \mathrm{~K}$ (c). A: range of typical BEA zeolite reflections. B: range of low-indexed $\mathrm{Ni}^{0}$ reflections; multiplied by a factor of 14 .

After deconvolution of overlapping peaks by profile fitting the FWHM of the metallic reflections could be satisfactorily estimated. Applying the well known Scherrer relation 
between FWHM of XRD peaks and particle diameter to the [111] and [200] reflections of $\mathrm{Ni}^{0}$ at $2 \theta=44.54^{\circ}$ and $51.8^{\circ}$, respectively, an average particle size of maximum $15 \mathrm{~nm}$ was obtained for the metallic nickel phase. Further, from differences in the intensity of the [111] reflection it can be concluded that reduced $\mathrm{Ni}$-[Al]BEA contains more metallic particles with diameters about $15 \mathrm{~nm}$ than $\mathrm{Ni}$-[A1,B]BEA samples subjected to the same reduction procedure.

In the diffraction pattern of reduced $\mathrm{Ni}$-[B]BEA reflections of metallic nickel did not appear, though this zeolite is readily reducible (see section 3.2.2.). The absence of metallic nickel reflections indicates that $\mathrm{Ni}^{0}$ particles are smaller than $5 \mathrm{~nm}$.

Transmission electron micrographs are in line with these observations. The Ni particles seen in the micrograph of reduced Ni-[A1,B]BEA-I (Fig. 3) are about 10-15 nm in size.

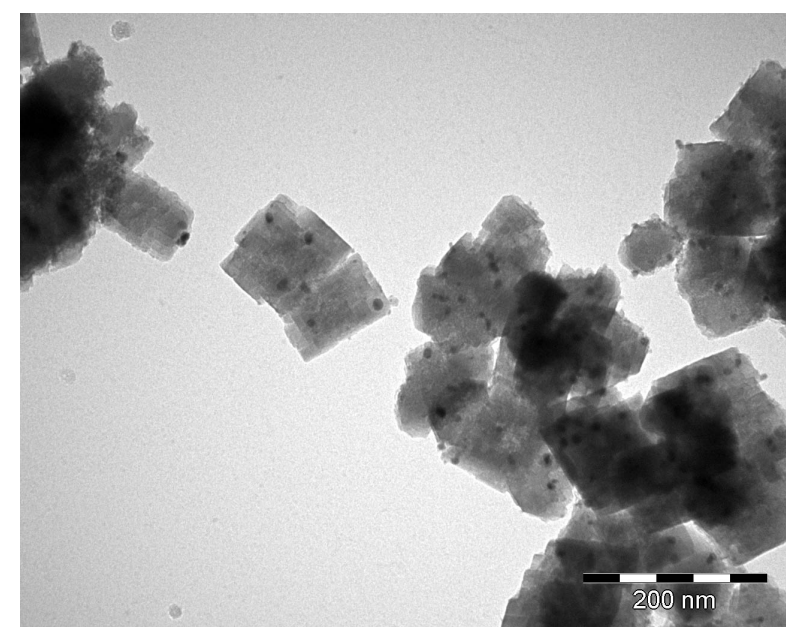

Fig. 3.Transmission electron micrograph of $\mathrm{Ni} / \mathrm{H}, \mathrm{Na}-[\mathrm{Al}, \mathrm{B}] \mathrm{BEA}-\mathrm{I}$ reduced with hydrogen at $723 \mathrm{~K}$

\subsubsection{Temperature-programmed reduction (TPR)}

In Fig. 4A are presented TPR curves of Ni,Na-[Al,B]BEA-I* after in-situ pretreatment in flowing nitrogen at 573 (curve b) and $723 \mathrm{~K}$ (curve c) and in oxidizing atmosphere (20 $\% \mathrm{O}_{2}$ in $\mathrm{He}$ ) at $723 \mathrm{~K}$ (curve d). The TPR profile of commercial (Aldrich) bulky nickeloxide $(37.4 \mathrm{mg}$ ) pretreated at $573 \mathrm{~K}$ in flowing nitrogen is shown in Fig. 4A,a for comparison. $\mathrm{NiO}$ is reduced in a single step between 523 and $673 \mathrm{~K}$ (the low-temperature shoulder and the relatively broad temperature range may be due to inhomogeneity in the particle size). Ni,Na-[Al,B]BEA-I* $(\mathrm{Al} / \mathrm{B}$ ratio $=2.6)$ pretreated at $573 \mathrm{~K}$ consumed hydrogen during the TPR run at temperatures ranging from 593 to $893 \mathrm{~K}$ (Fig. 4A,b). The reduction proceeded in at least two strongly overlapping but nevertheless distinct steps with maxima at 663 and $743 \mathrm{~K}$. As in the case of $\mathrm{NiO}$, the amount of consumed hydrogen was found to be (within the limits of the experimental error of $\sim 5 \%$ ) equivalent to the $\mathrm{Ni}^{2+}$ content, i.e. divalent nickel is completely reduced to the zerovalent state. An increase of the pretreatment temperature to $723 \mathrm{~K}$ resulted, under otherwise identical pretreatment conditions, in the disappearance of the peak with maximum at $663 \mathrm{~K}$, whereas the hightemperature reduction step was practically not affected (Fig. 4A,c). 


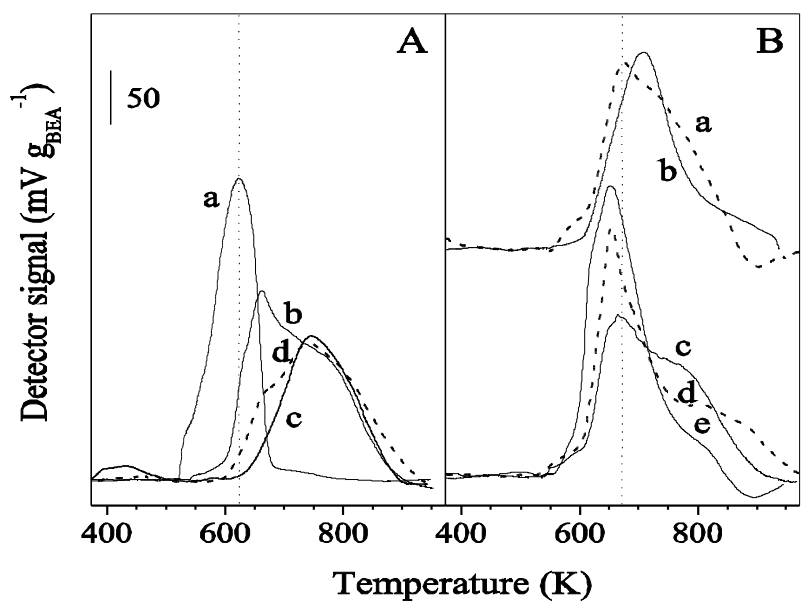

Fig. 4. TPR curves of $\mathrm{A}$ : $\mathrm{NiO}$ (a) and $\mathrm{Ni}, \mathrm{Na}-[\mathrm{Al}, \mathrm{B}] \mathrm{BEA}-\mathrm{I}^{*}$ pretreated in $\mathrm{N}_{2}$ flow at 573 (b) and $723 \mathrm{~K}$ (c) and in $20 \% \mathrm{O}_{2} / \mathrm{He}$ flow at $723 \mathrm{~K}$ (d); B: Ni,Na-[Al]BEA (a), Ni-[B]BEA (b), Ni,Na[Al,B]BEA-I (c), Ni,Na-[A1,B]BEA-II (d) and $\mathrm{Ni}^{-N_{4}}-[\mathrm{Al}, \mathrm{B}] \mathrm{BEA}-\mathrm{III}$ (e) pretreated in $\mathrm{N}_{2}$ at $573 \mathrm{~K}$.

Accordingly, the hydrogen consumption accounted for only a part of the total Ni content. Finally, when Ni,Na-[Al,B]BEA-I* was pretreated in an oxidizing atmosphere at $723 \mathrm{~K}$ prior to the TPR run, the low-temperature component of the TPR profile with maximum at $663 \mathrm{~K}$ decreased in intensity but did not completely disappeared (Fig. 4A,d).

The two distinct TPR peaks with maxima at 663 and $743 \mathrm{~K}$ (run b in Fig. 4A) can be tentatively attributed to easily reducible $\mathrm{NiOH}^{+}$species and to $\mathrm{Ni}^{2+}$ ions, respectively, since cation balances based on the relevant data in Table 1 evidence that into $\mathrm{Na}$ forms of aluminum and/or boron containing BEA zeolites part of the nickel is incorporated by nonstoichiometric ion exchange in form of $\mathrm{NiOH}^{+}$ions. The disappearance of the first TPR component (Fig. 4A,c) may be caused by auto-reduction (e.g. $\mathrm{NiOH}^{+} \leftrightarrow \mathrm{Ni}^{0}+\mathrm{H}^{+}+1 / 2 \mathrm{O}_{2}$ ) during the pretreatment in $\mathrm{N}_{2}$ between $573-723 \mathrm{~K}$. Then, the only partial elimination of the low-temperature TPR peak in run $d$ has to be attributed to the effect of the oxidizing pretreatment atmosphere counteracting the auto-reduction reaction.

$\mathrm{Ni}, \mathrm{Na}-[\mathrm{Al}]-\mathrm{BEA}$ exhibited after pretreatment at $573 \mathrm{~K}$ in flowing $\mathrm{N}_{2}$ a TPR profile (Fig. $4 \mathrm{~B}, \mathrm{a})$ very similar to that of $\mathrm{Ni}, \mathrm{Na}-[\mathrm{Al}, \mathrm{B}] \mathrm{BEA}-\mathrm{I}$ with the highest $\mathrm{Al} / \mathrm{B}$ ratio, i.e. 3.2 (Fig. $4 \mathrm{~B}, \mathrm{c})$. These two curves can be interpreted in the same way as curve b in Fig. 4A. In contrast, the $\mathrm{Ni}, \mathrm{NH}_{4}-[\mathrm{Al}, \mathrm{B}] \mathrm{BEA}-\mathrm{III}$ with the lowest $\mathrm{Al} / \mathrm{B}$ ratio $(0.58)$ exhibited a different TPR profile. The peak centered at about $653 \mathrm{~K}$ (run e) with a small high temperature shoulder indicates that this sample contains larger amount of easily reducible nickel ions than the zeolites with $\mathrm{Al} / \mathrm{B}$ ratios of 3.2 and 2.6. The TPR curve of Ni-[B]BEA shows a sole peak with a maximum at $708 \mathrm{~K}$. It is assumed that $\mathrm{Ni}^{2+}$ ions associated with tetrahedral boron units are reducible at lower temperature than those which compensate the negative framework charges of $\mathrm{AlO}_{4 / 2}$ units. In the literature it was also found that the interaction forces between nickel ions and zeolite framework influence the reducibility of nickel [23].

All prepared Ni-BEA zeolites without exception consumed during TPR runs hydrogen in amounts required for the reduction of all incorporated divalent $\mathrm{Ni}$ to the zerovalent state. A comprehensive investigation of the reducibility of $\mathrm{Ni}$ ions in beta zeolites was beyond the scope of this study. Anyway, it turned out that Ni-BEA zeolites containing Al and/or B as tetrahedral framework component are fully reducible under the conditions of the TPR technique at temperatures up to $873 \mathrm{~K}$. Applying isothermal long-term pretreatment in 
hydrogen atmosphere the required reduction temperature for conversion of these zeolites to bifunctional catalyst was significantly lower.

\subsubsection{FT-IR spectroscopy}

Fig. 5 exhibits the hydroxyl stretching spectra before (A) and pyridine ring vibration spectra after pyridine loading (B) of $\mathrm{NH}_{4}$-[A1,B]BEA-I (a-c) and Na-[A1,B]BEA-I (d-f) prior to $(\mathrm{a}, \mathrm{d})$ and after $(\mathrm{b}, \mathrm{e})$ ion exchange with nickel and after subsequent in-situ reduction with hydrogen at $723 \mathrm{~K}(\mathrm{c}, \mathrm{f})$. The hydroxyl stretching bands at 3735 and 3745 $\mathrm{cm}^{-1}$ (Fig. 5A) are generally assigned to "internal" silanol groups associated with framework vacancies (hydroxyl nests) and to structure-terminating hydroxyls at the crystal surface, respectively. Both species are irrelevant to the subject treated in this paper.

Partial replacement of ammonium ions in $\mathrm{NH}_{4}-[\mathrm{Al}, \mathrm{B}] \mathrm{BEA}$ by ion exchange with nickel is clearly evidenced by the intensity decrease of the band at 3610 and $1546 \mathrm{~cm}^{-1}$ typical of bridged hydroxyls and pyridinium ions, respectively (cf. spectra a and b in Figs. 5A and 5B). Further evidence is provided by the concomitant development of the band at $1449 \mathrm{~cm}^{-}$ ${ }^{1}$ indicative of pyridine coordinatively bound to Ni cations occupying ion-exchange sites in zeolites. According to expectation, reduction of incorporated nickel ions with hydrogen resulted in a nearly complete disappearance of the band at $1449 \mathrm{~cm}^{-1}$ and in the full restoration of the original intensity of the band at $3610 \mathrm{~cm}^{-1}$ (cf. spectra $\mathrm{b}$ and $\mathrm{c}$ in Figs.

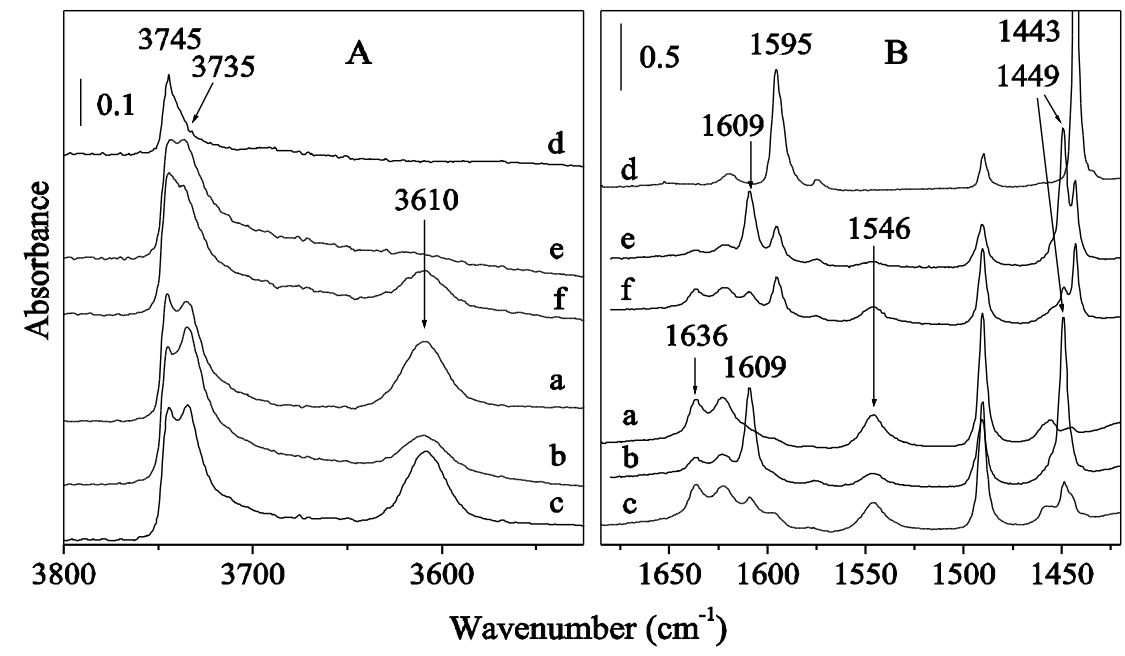

Fig. 5. A: hydroxyl stretching spectra of $\mathrm{NH}_{4}-[\mathrm{Al}, \mathrm{B}] \mathrm{BEA}-\mathrm{I}$ (a-c) and $\mathrm{Na}-[\mathrm{Al}, \mathrm{B}] \mathrm{BEA}-\mathrm{I}$ (d-f) after pretreatment at $723 \mathrm{~K}$ in high vacuum $(\mathrm{a}, \mathrm{c})$, ion-exchange with nickel $(\mathrm{b}, \mathrm{d})$ and reduction in situ in flowing hydrogen at $723 \mathrm{~K}(\mathrm{c}, \mathrm{f})$. B: pyridine ring vibration spectra of the respective zeolites after loading with pyridine and degassing at $373 \mathrm{~K}$

5A and 5B), i.e. in the re-establishment of the bridged hydroxyls. Accordingly, the ion exchange of nickel into Na-[A1,B]BEA-I is evidenced by the creation of the band at 1449 $\mathrm{cm}^{-1}$ and the strong intensity decrease of the $1443 \mathrm{~cm}^{-1}$ band indicative of sodium cations in zeolites (cf. spectra d and e in Fig. 5B). Reduction with hydrogen results in the creation of Brønsted-acid sites as indicated by the development of the band at 3610 and the strong intensity loss of the band at $1449 \mathrm{~cm}^{-1}$. In reduced nickel exchanged BEA zeolites all of the Brønsted acid sites are accessible to pyridine as evidenced by the complete disappearance of the $\mathrm{OH}$ band at $3610 \mathrm{~cm}^{-1}$ (not shown).

Similar spectral features were observed for the other prepared BEA zeolites after 
identical treatments.

The integrated intensity of the band at $3610 \mathrm{~cm}^{-1}$ was considered to be proportional to the amount of Brønsted acid sites and related to the corresponding band intensity in the spectrum of $\mathrm{NH}_{4}$-[Al]BEA considered as standard with a bridged hydroxyl content of 1.04 mmol g-1 (Table 1). Brønsted acid contents estimated in this way for reduced Ni-BEA

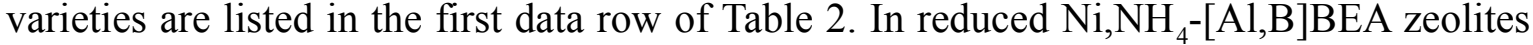
(I and III) the amount of bridged hydroxyls corresponded rather well with that found for the respective $\mathrm{NH}_{4}$-[Al,B]BEA prior to nickel ion exchange. Thus, all acidic sites previously eliminated by incorporation of nickel are restored upon reduction.

Into Na-[Al]BEA $0.57 \mathrm{mmol} \mathrm{g}^{-1}$ nickel was introduced by ion exchange while mostly all of the sodium cations were replaced (Table 1). The Brønsted acid site content of the resulting $\mathrm{Ni}, \mathrm{Na}$-[Al]BEA zeolite amounted after reduction to $0.94 \mathrm{mmol} \mathrm{g}^{-1}$ (Table 2). A satisfactory ion balance can be established with the assumption that $33 \%$ of the incorporated nickel is present in form of $\mathrm{NiOH}^{+}$species. Results presented in the previous section also suggested "over-exchange" of nickel into Ni,Na-[Al,B]BEA-I, i.e. the incorporation of $\mathrm{NiOH}^{+}$.

In contrast to boron-free BEA zeolite, $\mathrm{Ni}, \mathrm{Na}-[\mathrm{Al}, \mathrm{B}] \mathrm{BEA}-\mathrm{I}$ was found to contain after reduction much less bridged hydroxyls $\left(0.50 \mathrm{mmol} \mathrm{g}^{-1}\right)$ than the corresponding $\mathrm{Ni}^{-} \mathrm{NH}_{4^{-}}$ [A1,B]BEA-I $\left(0.86 \mathrm{mmol} \mathrm{g}^{-1}\right)$ and a great amount $\left(0.35 \mathrm{mmol} \mathrm{g}^{-1}\right)$ of residual, i.e. not exchanged sodium (Table 2 and 1 , respectively). The sum $\left(0.85 \mathrm{mmol} \mathrm{g}^{-1}\right)$ of protons and sodium cations corresponds well with the framework aluminum content $\left(0.89 \mathrm{mmol} \mathrm{g}^{-1}\right)$. Thus, it can be concluded that in boron containing BEA zeolites residual sodium ions occupy sites associated with tetrahedral aluminum and not those related to framework boron which are predominantly occupied by nickel ions. The establishment of an ion balance for Ni,Na-[A1,B]BEA-I from the data given in Table 1 gives evidence that also in this case about one third of the incorporated nickel is present in form of species created via non-stoichiometric ion exchange.

\subsection{Hydroconversion of n-heptane}

\subsubsection{Hydroisomerization and hydrocracking}

$\mathrm{Ni} / \mathrm{H}-[\mathrm{Al}] \mathrm{BEA}$ and $\mathrm{Ni} / \mathrm{H}-[\mathrm{Al}, \mathrm{B}] \mathrm{BEA}$ zeolites with molar $\mathrm{Ni} /($ acid site) ratios of $0.5-1.2$ proved to be catalysts with appropriate activity for hydroconversion of heptane. At conversion levels up to $15-30 \%$ the isomerization selectivity reached practically $100 \%$ (Figs. 6, 8). 

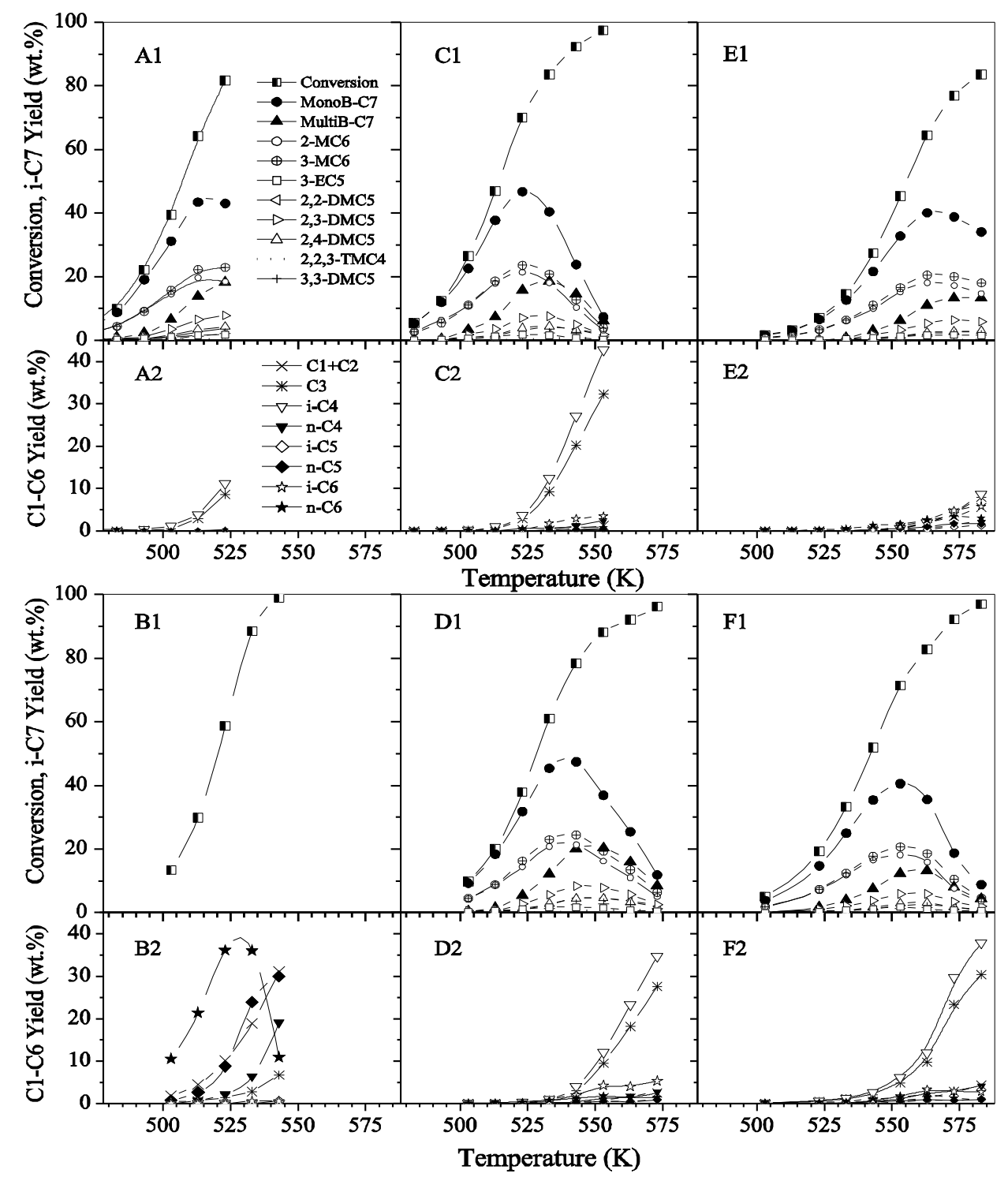

Fig. 6. Hydroconversion of heptane and yields of $\mathrm{C} 7$ isomers and cracking products over $\mathrm{Ni} / \mathrm{H}, \mathrm{Na}-$ [A1]BEA (A1, A2), Ni/H-[B]BEA (B1, B2), Ni/H,Na-[A1]BEA-p (C1, C2), Ni/H,Na-[A1,B]BEA-I (D1, D2), Ni/H-[A1,B]BEA-II (E1, E2), Ni/H-[A1,B]BEA-III (F1, F2) as a function of temperature. $\mathrm{H}_{2} / \mathrm{C} 7=19.6 ; \mathrm{p}_{\text {tot. }}=5$ bar; contact time $=0.73 \mathrm{~g}_{\mathrm{cat}} \mathrm{g}^{-1}{ }_{\mathrm{n}-\mathrm{C} 7} \mathrm{~h}$.

However, for industrial processes generally higher conversion degrees are in demand. Therefore, for comparison of the efficiency of the catalysts the results of typical catalytic runs with conversion degrees of 60-70\% were listed in Table 2. Naturally, hydrocracking is not further negligible at such high conversion levels. Ni/H,Na-[Al]BEA was found to be the most active catalyst among the zeolites used in this study. Both hydroisomerization and hydrocracking started at significantly lower temperatures than over the other BEA varieties (Figs. 6A1, A2). However, the yield of heptane isomers is low due to relatively strong cracking (Fig. 7, Table 2). 


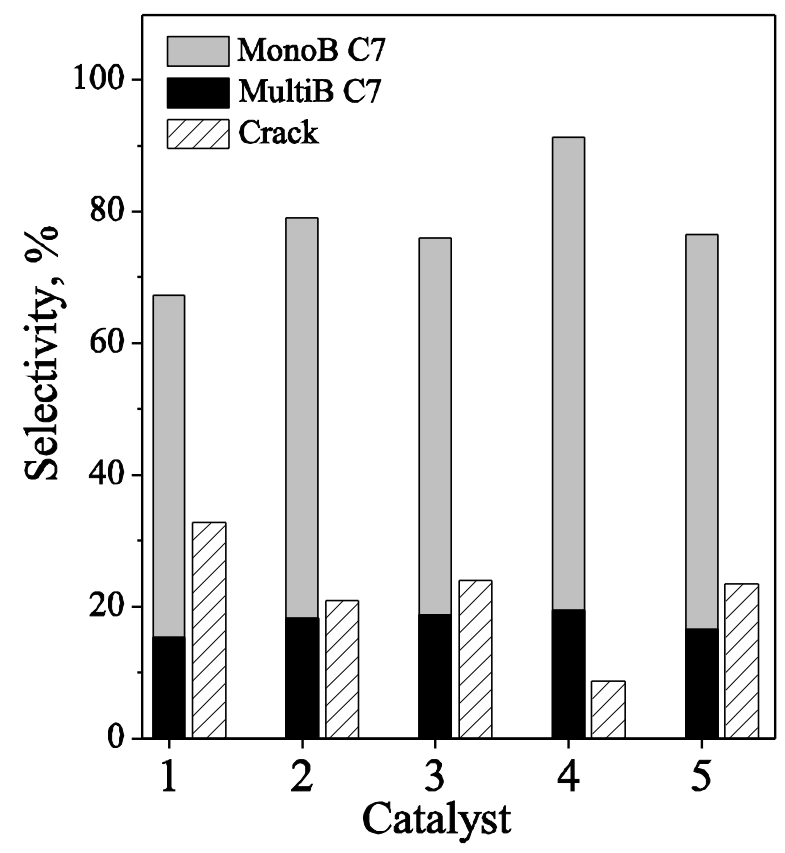

Fig. 7. Selectivities to monobranched $\mathrm{C} 7$ and multibranched $\mathrm{C} 7$ isomers as well as crack products in $\mathrm{n}$-heptane hydroconversion over different $\mathrm{Ni} / \mathrm{H}-\mathrm{BEA}$ catalysts $((1): \mathrm{Ni} / \mathrm{H}, \mathrm{Na}-[\mathrm{Al}] \mathrm{BEA}$, (2): Ni/H,Na-[Al]BEA-p, (3): Ni/H-[Al,B]BEA-I, (4): Ni/H,Na-[Al,B]BEA-I, (5): Ni/H-[Al,B]BEA-III) at about $65 \%$ conversion at $533 \mathrm{~K}$ and $\mathrm{p}_{\text {tot }}=5$ bar (Table 2 ).

It is generally known that the isomerization/crack selectivity of bifunctional catalysts crucially depends on, and can be controlled by, appropriately balanced ratios of the acidic and hydrogenating component. Thus, the zeolite was after incorporation of Ni subjected to an ion exchange with sodium in order to suppress hydrocracking by decreasing the concentration of Brønsted acid sites. The decrease of the acidic sites by $20 \%$ from 0.94 mmol $\mathrm{g}^{-1}$ in $\mathrm{Ni} / \mathrm{H}, \mathrm{Na}-[\mathrm{Al}] \mathrm{BEA}$ to $0.75 \mathrm{mmol} \mathrm{g}^{-1}$ in $\mathrm{Ni} / \mathrm{H}, \mathrm{Na}-[\mathrm{Al}] \mathrm{BEA}-\mathrm{p}$ resulted in a significant increase of heptane isomers (mainly monobranched isomers) and in a similarly pronounced decrease of crack products, i.e. in a considerable increase of the isomerization selectivity (Catalyst 1 and 2 in Fig. 7, Table 2). 
Table 2 Product distribution (mol \%) at about $65 \%$ conversion of heptane over bifunctional $\mathrm{Ni} / \mathrm{H}-$ Beta catalysts at $533 \mathrm{~K}$ and $\mathrm{p}_{\text {tot }}=5$ bar.

\begin{tabular}{|c|c|c|c|c|c|c|c|}
\hline Sample & $\begin{array}{l}\mathrm{Ni} / \mathrm{H}, \mathrm{Na}- \\
{[\mathrm{Al}] \mathrm{BEA}}\end{array}$ & $\begin{array}{l}\mathrm{Ni} / \mathrm{H}, \mathrm{Na}- \\
{[\mathrm{Al}] \mathrm{BEA}} \\
-\mathrm{p}\end{array}$ & $\begin{array}{l}\mathrm{Ni} / \mathrm{H}- \\
\text { [Al,B] } \\
\text { BEA-I }\end{array}$ & \multicolumn{2}{|c|}{$\begin{array}{l}\text { Ni/H,Na- } \\
{[\mathrm{Al}, \mathrm{B}] \mathrm{BEA}-\mathrm{I}^{1)}}\end{array}$} & \multicolumn{2}{|c|}{$\begin{array}{l}\mathrm{Ni} / \mathrm{H}- \\
\text { [Al,B]- } \\
\text { BEA-IIIb }\end{array}$} \\
\hline $\mathrm{OH}\left(\mathrm{mmol} \mathrm{g}{ }^{-1}\right)$ & 0.94 & 0.75 & 0.86 & \multirow{2}{*}{\multicolumn{2}{|c|}{$\begin{array}{c}0.50 \\
1.00 \\
0.733\end{array}$}} & \multicolumn{2}{|l|}{0.40} \\
\hline $\mathrm{Ni} / \mathrm{OH}$ & 0.60 & 0.75 & 0.55 & & & \multicolumn{2}{|l|}{1.20} \\
\hline Contact time (h) & 0.246 & 0.366 & 0.731 & & & \multicolumn{2}{|l|}{1.460} \\
\hline Conversion (wt\%) & 61.8 & 67.6 & 69.2 & 60.8 & 61.7 & \multicolumn{2}{|l|}{59.2} \\
\hline $\mathrm{S}$ i-C7 & 67.2 & 79.0 & 76.0 & 91.3 & 89.0 & \multicolumn{2}{|l|}{76.5} \\
\hline $\begin{array}{l}\mathrm{C} 1 \\
\mathrm{C} 3\end{array}$ & $\begin{array}{l}0.2 \\
12.2\end{array}$ & $\begin{array}{l}1.3 \\
7.1\end{array}$ & $\begin{array}{l}0.9 \\
9.0\end{array}$ & $\begin{array}{l}1.4 \\
2.0\end{array}$ & $\begin{array}{l}1.5 \\
2.6\end{array}$ & \multicolumn{2}{|l|}{1.6} \\
\hline $\mathrm{i}-\mathrm{C} 4$ & 12.3 & 7.0 & 8.4 & 1.7 & 2.5 & \multicolumn{2}{|l|}{6.9} \\
\hline $\mathrm{n}-\mathrm{C} 4$ & 0.3 & 0.3 & 0.6 & 0.2 & 0.3 & \multicolumn{2}{|l|}{0.4} \\
\hline $\mathrm{i}-\mathrm{C} 5$ & 0 & 0 & 0 & 0 & 0 & \multicolumn{2}{|l|}{0} \\
\hline $\mathrm{n}-\mathrm{C} 5$ & 0 & 0 & 0 & 0 & 0 & \multicolumn{2}{|l|}{0.3} \\
\hline$\sum \mathrm{C} 6$ & 0.2 & 1.3 & 0.9 & 1.40 & 1.4 & 1.0 & Equilibr. \\
\hline 2-MC6 & 14.5 & 18.5 & 17.9 & 20.0 & 19.6 & 16.3 & 19.6 \\
\hline 3-MC6 & 16.2 & 21.1 & 20.3 & 22.1 & 22.1 & 18.0 & 17.8 \\
\hline 3 -EC5 & 1.3 & 1.4 & 1.4 & 1.6 & 1.5 & 1.2 & 2.1 \\
\hline 2,2-DMC5 & 1.7 & 2.3 & 2.4 & 2.4 & 2.3 & 1.6 & 9.5 \\
\hline 2,3-DMC5 & 4.8 & 5.6 & 6.2 & 5.4 & 5.3 & 4.8 & 25.4 \\
\hline 2,4-DMC5 & 2.2 & 3.0 & 3.1 & 2.7 & 2.8 & 2.3 & 5.8 \\
\hline 2,2,3-TMC4 & 0.1 & 0.1 & 0 & 0 & 0 & 0 & 2.3 \\
\hline 3,3-DMC5 & 0.7 & 1.4 & 1.3 & 1.3 & 1.3 & 1.1 & 7.6 \\
\hline $\mathrm{n}-\mathrm{C} 7$ & 33.3 & 29.7 & 27.6 & 37.8 & 36.3 & 37.2 & 9.9 \\
\hline$\sum \mathrm{i}-\mathrm{C} 7$ & 41.5 & 53.4 & 52.6 & 55.5 & 54.9 & 45.3 & \\
\hline MonoB C7 & 32.0 & 41.0 & 39.6 & 43.7 & 43.2 & 35.5 & \\
\hline MultiB C7 & 9.5 & 12.4 & 13.0 & 11.8 & 11.7 & 9.8 & \\
\hline $\mathrm{C} 4 / \mathrm{C} 3$ & 1.03 & 1.03 & 1.00 & 0.95 & 1.08 & 1.00 & \\
\hline $\mathrm{C} 1 /(2 * \mathrm{C} 5+\mathrm{C} 6)$ & 1.00 & 0.99 & 1.00 & 1.00 & 1.07 & 1.00 & \\
\hline
\end{tabular}

1) TOS: $10 \mathrm{~h}$ (left column); $35 \mathrm{~h}$ (right column) 
$\mathrm{Ni} / \mathrm{H}-[\mathrm{Al}, \mathrm{B}] \mathrm{BEA}-\mathrm{I}$ with an $\mathrm{Al} / \mathrm{B}$ ratio of 3.2 contained about the same amount of Brønsted acid sites as $\mathrm{Ni} / \mathrm{H}, \mathrm{Na}-[\mathrm{Al}] \mathrm{BEA}$ and no significant difference in the acid strength was found (vide infra). Nevertheless, it was significantly less active, but exhibited the highest selectivity to isomerization (Catalyst 4 in Fig. 7, and Figs. 8A3, B3). Incorporation of a greater amount of framework boron $(\mathrm{Ni} / \mathrm{H}-[\mathrm{Al}, \mathrm{B}] \mathrm{BEA}-\mathrm{III}, \mathrm{Al} / \mathrm{B}=0.58)$ resulted in a significant decrease in acid site density and correspondingly low activity, but did not lead to further increase of the isomerization selectivity (Catalyst 5 in Fig. 7 and Fig. 8C3).
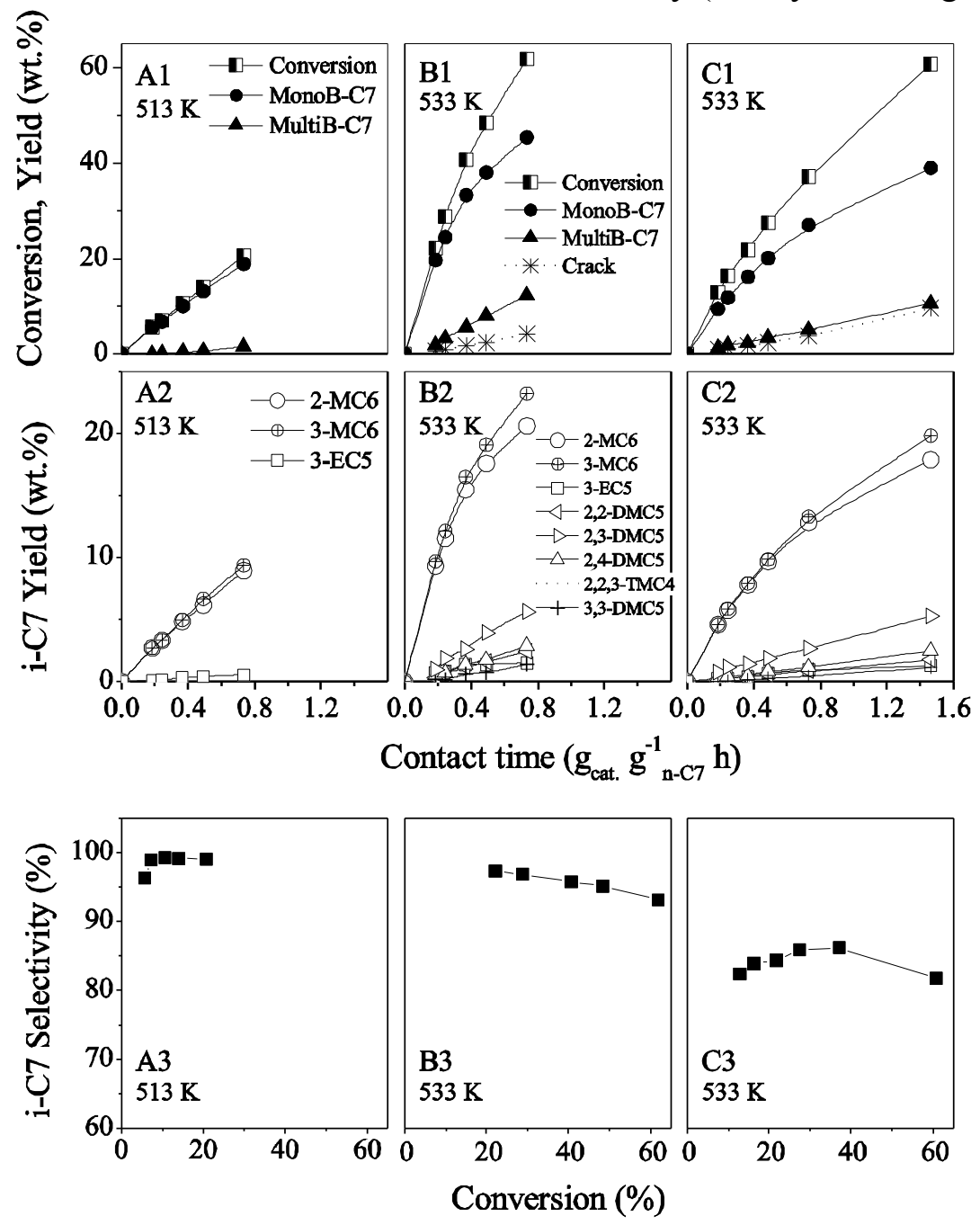

Fig. 8. Hydroconversion of heptane, yields of products and selectivity to i-C7 over $\mathrm{Ni} / \mathrm{H}, \mathrm{Na}-$ [A1,B]BEA-I at 513 (A1, A2, A3) and $533 \mathrm{~K}$ (B1, B2, B3) and over Ni/H-[A1,B]BEA-III at $533 \mathrm{~K}$ $(\mathrm{C} 1, \mathrm{C} 2, \mathrm{C} 3)$ as a function of contact time and conversion.

Ion exchange of nickel into $\mathrm{Na}-[\mathrm{Al}, \mathrm{B}] \mathrm{BEA}-\mathrm{I}$ resulted in a product in which a considerable part of the sodium ions is retained on exchange sites associated with tetrahedral framework aluminum. Nevertheless, even more nickel was incorporated than in the stoichiometrically exchanged $\mathrm{Ni}, \mathrm{NH}_{4}-[\mathrm{Al}, \mathrm{B}] \mathrm{BEA}-\mathrm{I}$, i.e. "over-exchange" occurred (section 3.2.2.). Thus, the acid function is further reduced without a simultaneous decrease of the hydrogenation/dehydrogenation activity. These catalysts proved to be of optimum composition with respect to the isomerization selectivity (Table 2).

As to deactivation, $\mathrm{Ni} / \mathrm{H}, \mathrm{Na}-[\mathrm{Al}, \mathrm{B}] \mathrm{BEA}-\mathrm{I}$ was by far the most resistant catalysts among the tested zeolites. Even after a time-on-stream of $35 \mathrm{~h}$ at about $60-70 \%$ conversion no catalyst deactivation was observed (Table 2). The other catalysts listed in Table 2 underwent a slight deactivation of about $5 \%$ in the initial operation period and approached 
a stationary activity after about 10 hours.

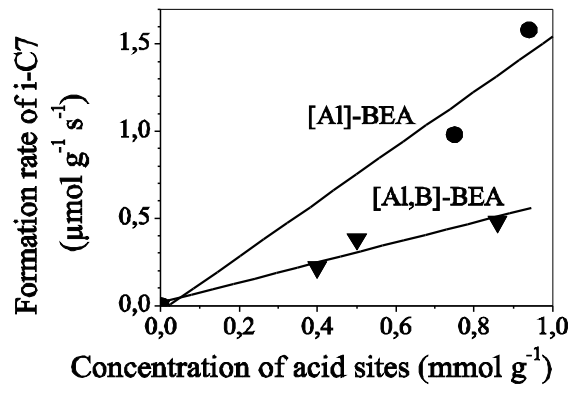

Fig. 9. Formation rate of $\mathrm{i}-\mathrm{C} 7$ for catalysts vs. acid site concentration in zeolites listed in Table 2

The formation rate of i-heptane up to conversion degrees of about $10 \%$ correlate satisfactorily with the concentration of acid sites (Fig. 9). However, the slope of this relation is much steeper for $[\mathrm{Al}] \mathrm{BEA}$ than for $[\mathrm{Al}, \mathrm{B}] \mathrm{BEA}$. Further, at low conversion the reaction rates $(\mathrm{k})$ for hydroisomerization to 2-methyl- and 3-methylhexane are identical over Ni/H,Na-[Al]BEA and Ni/H,Na-[Al,B]BEA-I (Figs. 10A and C, respectively), but at

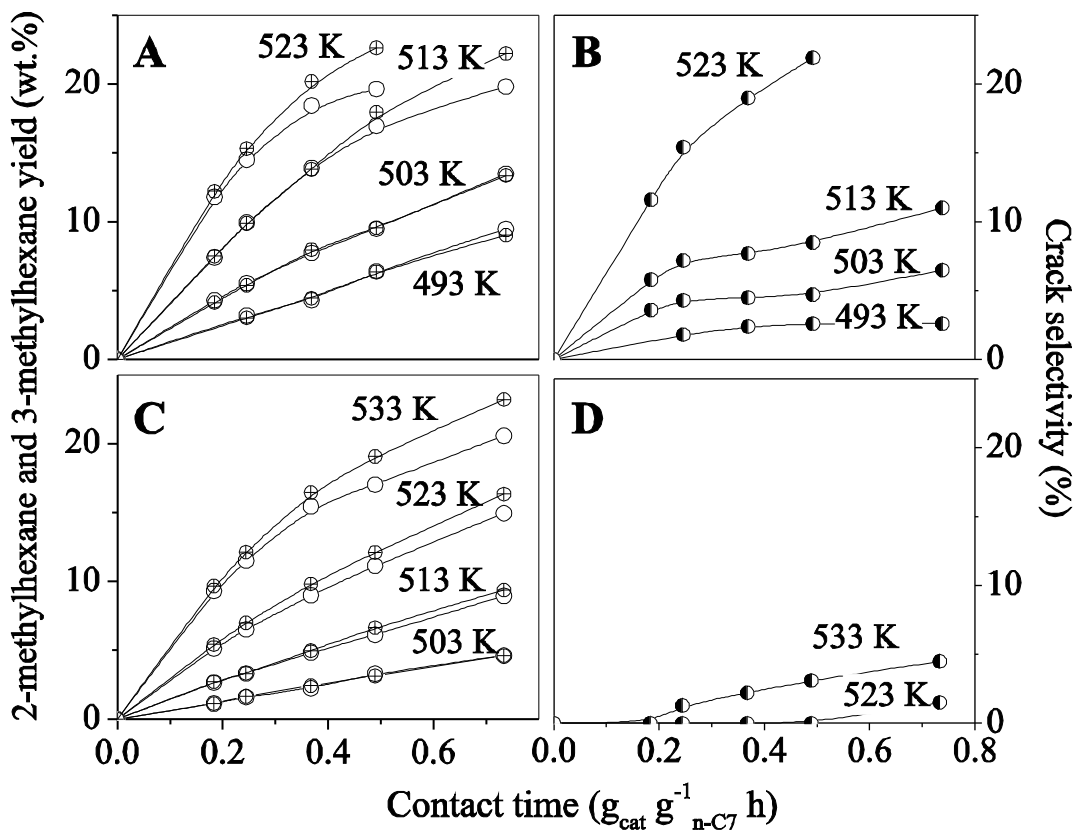

Fig. 10. Formation of 2-methylhexane $(O)$ and 3-methylhexane $(\oplus)(A, C)$ and selectivity to cracking products $(\mathrm{B}, \mathrm{D})$ vs. contact time over $\mathrm{Ni} / \mathrm{H}, \mathrm{Na}-[\mathrm{Al}] \mathrm{BEA}(\mathrm{A}, \mathrm{B})$ and $\mathrm{Ni} / \mathrm{H}, \mathrm{Na}-[\mathrm{Al}, \mathrm{B}] \mathrm{BEA}-\mathrm{I}$ $(\mathrm{C}, \mathrm{D})$ at different temperatures.

higher conversion degrees the yield vs. contact time plots deviate in favor of the 3-methyl isomer (This phenomenon is discussed in section 3.3.4.). Upon incorporation of boron into the framework and reducing the framework aluminum content results in a significant decrease in hydrocracking activity (Fig. 10B and D).

Arrhenius plots of the initial reaction rates are linear (Fig. 11). The apparent activation energies calculated from the slope of the straight lines were found to be different for conversion over [Al]BEA $\left(119 \mathrm{~kJ} \mathrm{~mol}^{-1}\right)$ and [Al,B]BEA catalysts $\left(160 \mathrm{~kJ} \mathrm{~mol}^{-1}\right)$. On the other hand, neither DRIFT spectra of adsorbed $\mathrm{N}_{2}$ nor temperature-programmed desorption of ammonia (section 3.1) and pyridine (see Ref. 17) gave any indication of differences in 
the acid strength of bridged hydroxyls in BEA zeolites containing framework boron in different amounts. Consequently, the decrease in the isomerization rate and the increase of the apparent activation energy upon incorporation of boron may be attributed to differences in the heat of adsorption.

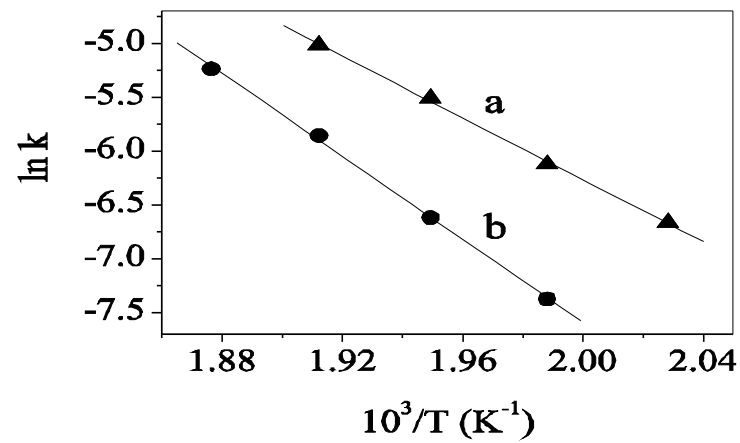

Fig. 11. Arrhenius plots of reaction constants for $n-h e p t a n e$ over $\mathrm{Ni} / \mathrm{H}, \mathrm{Na}-[\mathrm{Al}] \mathrm{BEA}$ (a) and $\mathrm{Ni} / \mathrm{H}, \mathrm{Na}-[\mathrm{Al}, \mathrm{B}] \mathrm{BEA}-\mathrm{I}$ (b) derived from the yield vs. contact time curves in Fig. 10.

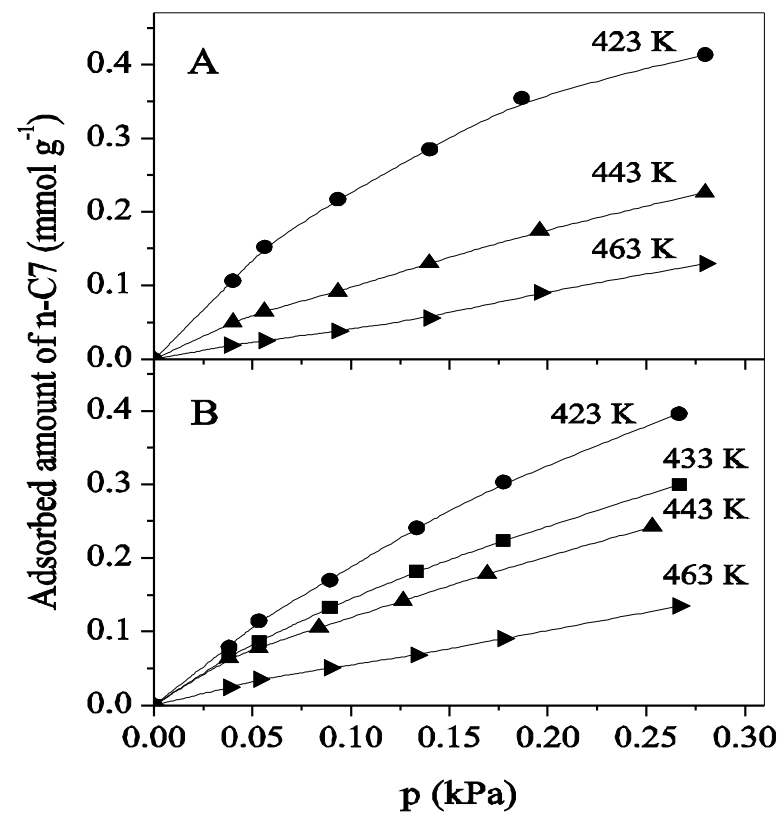

Fig. 12. Adsorption isotherms for $n-h e p t a n e$ on $\mathrm{NH}_{4}-[\mathrm{Al}] \mathrm{BEA}(\mathrm{A})$ and $\mathrm{NH}_{4}-[\mathrm{Al}, \mathrm{B}] \mathrm{BEA}-\mathrm{I}(\mathrm{B})$ at different temperatures.

Adsorption isotherms for $\mathrm{n}$-heptane on $\mathrm{NH}_{4}$-[Al]BEA and $\mathrm{NH}_{4}$-[Al,B]BEA-I are shown in Figs. 12A and $\mathrm{B}$, respectively. The limiting isosteric heat of adsorption at zero coverage $\left(\mathrm{Q}_{0}\right)$ can be obtained according to the isochoric van't Hoff equation from the temperature dependence of Henry's constant which, in its logarithmic form, can be written as

$$
\ln \mathrm{K}_{\text {Henry }}=-\Delta \mathrm{Q}_{0} / \mathrm{RT}
$$

where $\mathrm{K}_{\text {Henry }}$ equals the initial slope of the adsorption isotherm. Henry's constants derived 
from the isotherms in Fig. 12 are plotted according to equation (1) in Fig. 13. The initial isosteric adsorption heats for $n$-heptane calculated from the slopes of the straight lines a and $\mathrm{b}$ amount to -78 and $-45 \mathrm{~kJ} \mathrm{~mol}^{-1}$ on $\mathrm{NH}_{4}-[\mathrm{Al}] \mathrm{BEA}$ and $\mathrm{NH}_{4}-[\mathrm{Al}, \mathrm{B}] \mathrm{BEA}-\mathrm{I}$, respectively. The adsorption heat obtained for the boron-free zeolite corresponds sufficiently well with literature data experimentally determined $\left(-73 \mathrm{~kJ} \mathrm{~mol}^{-1}\right)$ and theoretically calculated $\left(-75 \mathrm{~kJ} \mathrm{~mol}^{-1}\right)$ for BEA zeolite in Refs. 14 and 24, respectively.

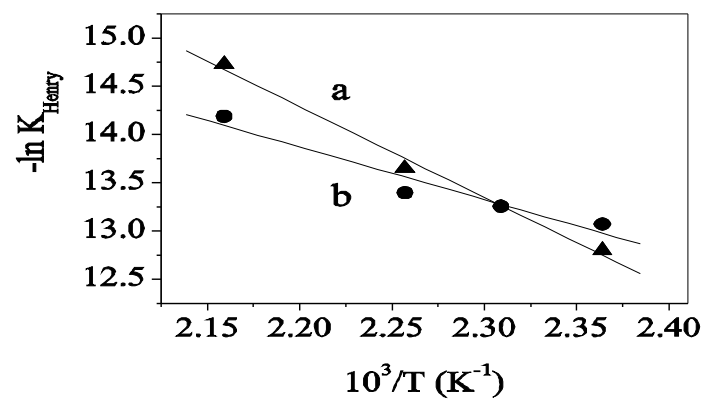

Fig. 13. Van't Hoff plots of the temperature dependence of Henry's law constants for n-heptane on $\mathrm{NH}_{4}$-[Al]BEA (a) and $\mathrm{NH}_{4}$-[Al,B]BEA-I (b).

Taking into account the contribution of the heat of adsorption to the energy of activation of reactant molecules

$$
\mathrm{E}_{\text {apparent }}=\mathrm{E}_{\text {intrinsic }}+\mathrm{Q}_{0} \text {, }
$$

the intrinsic activation energies for isomerization of $n$-heptane to methyl-hexanes over $\mathrm{Ni}, \mathrm{Na}-[\mathrm{Al}] \mathrm{BEA}$ and Ni,Na-[A1,B]BEA-I (197 and $205 \mathrm{~kJ} \mathrm{~mol}^{-1}$, respectively) were found to be equal within the limit of experimental errors $(5 \%)$. This result is fully in line with IR spectroscopic and ammonia TPD results (vide supra) which gave evidence that Brønsted acid sites of BEA zeolites involved in the hydroisomerization of alkanes are not affected in respect of the intrinsic acid strength probed with nitrogen and the acid-base behavior towards stronger bases (ammonia, pyridine) by incorporation of framework boron. Thus, the significant increase of the isomerization selectivity upon boron incorporation into tetrahedral framework sites must probably be attributed to particular arrangements of adsorbed reactant molecules around the catalytically active sites. The experimental results obtained up to now are not sufficient yet for a properly substantiated interpretation of adsorption phenomena resulting in the observed selectivity changes.

\subsubsection{Hydrogenolysis}

Hydrogenolysis played only a minor role in the hydroconversion of n-heptane over aluminum and aluminum/boron containing BEA zeolites. Over boron-free Ni-[Al]BEA and $\mathrm{Ni}-[\mathrm{Al}, \mathrm{B}] \mathrm{BEA}$ zeolites hydrogenolysis contributed to the total conversion by only 0.2 and $1-1.5 \%$, respectively (Table 2 ). According to expectation the reaction products methane and n-hexane were formed at low conversion degrees in nearly equimolar amounts. Under more severe reaction conditions (longer contact time, higher temperature) branched hexanes were formed in increasing amounts at the expense, i.e. by isomerization, of the primary reaction product n-hexane (Fig. 6C2, and D2). Over $\mathrm{Ni}^{-N_{4}}{ }_{4}^{-}[\mathrm{Al}, \mathrm{B}] \mathrm{BEA}-\mathrm{III}$ also some n-pentane could be detected (Table 2) the concentration of which increased with increasing contact time at the expense of the hexane yield. The molar amount of methane corresponded well with the molar yield of hexane plus twice n-pentane (Table 2). Hence, $\mathrm{n}$-hexane and methane are primary hydrogenolysis products, and branched hexanes and npentane are formed from n-hexane by consecutive isomerization and progressive 
hydrogenolysis, respectively.

Ni-exchanged [B]BEA exhibited a catalytic behavior fundamentally different from the other zeolite varieties studied in this paper. This material was completely inactive for hydroisomerization as evidenced by the lack of heptane isomers as reaction products. Surprisingly, hydrogenolysis was found to be by far the most predominant reaction path, moreover with a conversion degree comparable to those observed in the same temperature range for hydroisomerization over other BEA varieties. Exclusively normal paraffins with shorter C-chain are formed (Fig. 6, Table 2). The product distribution with increasing reaction temperatures and contact times (not shown) clearly reveal that $n$-hexane, propane and methane are primary reaction products, while n-pentane originated from n-hexane in a consecutive hydrogenolysis reaction. The high hydrogenolysis activity is probably due to the extremely small size of nickel particles in reduced Ni-[B]BEA (section 3.2.1.). At short contact times n-butane and propane were formed in very small, but equimolar amounts. However, at longer contact times the molar yield of n-butane surpassed more and more that of propane. Thus, propane and an equimolar part of n-butane are probably due to cracking of n-heptane, and hydrogenolysis of the secondary reaction product n-pentane accounts for the n-butane excess. Accordingly, the molar amount of methane corresponded at any reaction temperature and contact time to the sum of (hexane $+2 \mathrm{x}$ pentane $+3 \mathrm{x}$ excess butane). The minor cracking probably proceeds on acid sites associated with traces of framework aluminum.

\subsubsection{Mechanism of hydroisomerization over boron-substituted BEA varieties}

Product distributions at increasing reaction temperatures (Fig. 6) and plots of yield vs. contact time (Fig. 8) clearly reveal that only mono-branched isomers (2- and 3methylhexane, 3-ethylpentane) are primary reaction products of the hydroisomerization of n-heptane. The more or less pronounced initial inhibition period in yield/contact time curves of multi-branched reaction products evidences that these compounds are formed in consecutive reactions from methylhexanes.

Some decades ago Weitkamp proposed (e.g. in $[2,3])$ an isomerization mechanism in which corner-protonated cyclopropane (CPCP) ions play the key role as catalytically active intermediates. The model illustrated in reaction scheme 1 , route 1 for $n$-heptane conversion involves as initial step ring closure between a charge-bearing $\mathrm{C}$-atom of a classical secondary carbenium ion (1a) and the $\mathrm{C}$-atom in $\beta$-position relative to the charged carbon resulting in a cyclopropylcarbonium ion $(1 \mathrm{~b})$. Then the protonated cyclopropane with the positive charge at the C-atom free of alkyl substituents (1c) is formed by proton jump. Subsequent ring opening leads directly to secondary 2-methyl- and 3methylhexylcarbenium ions (1d). Finally, the resulting branched secondary carbenium ion converts to the tertiary ion (1e) via conventional hydride shift. For energetic reasons ring opening reactions resulting in primary carbenium ions are considered to be completely blocked, i.e. skeletal isomerization proceeds exclusively via cyclic propylcarbonium ions containing not more than one unsubstituted $\mathrm{C}$-atom in the ring. 
(1)

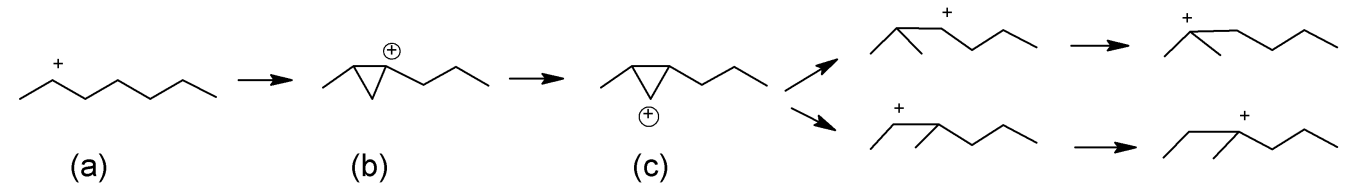

(d)

(e)

(2)

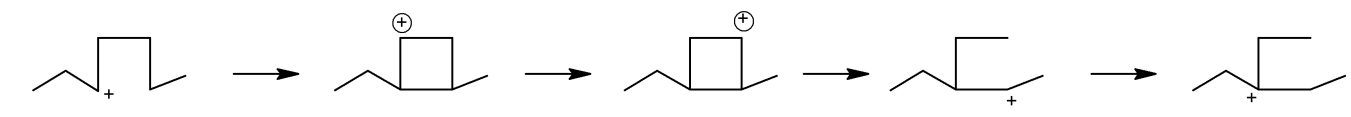

(3)

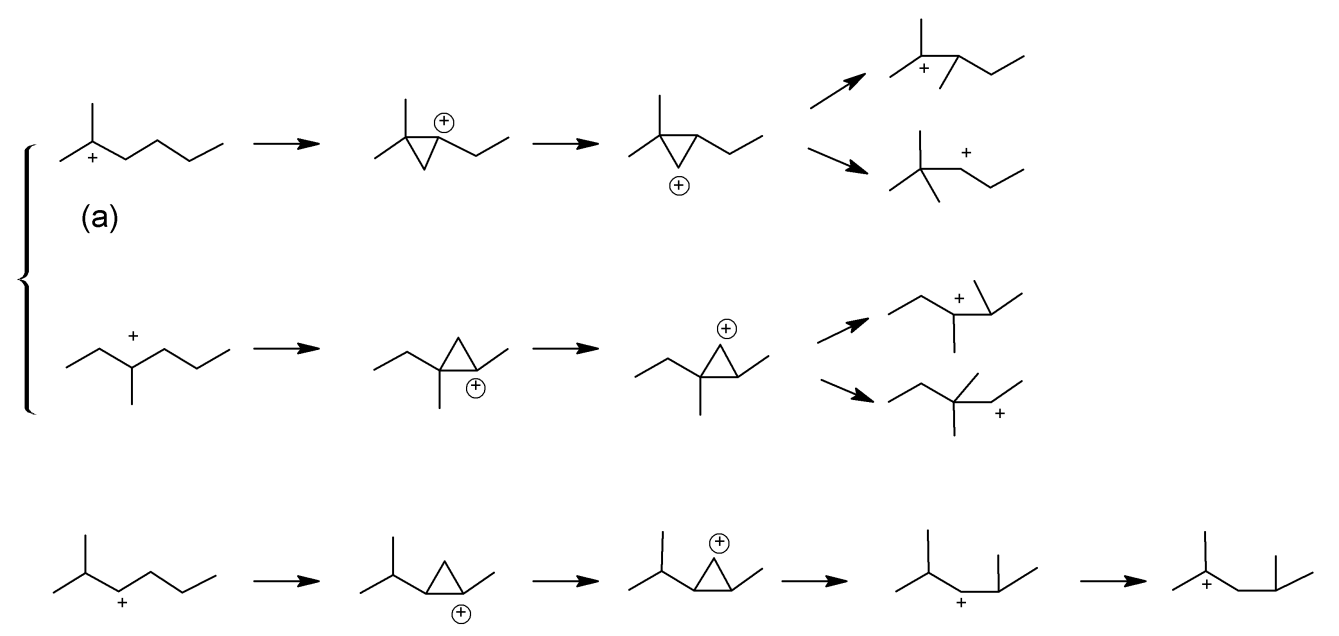

(a)

+ charge in carbenium ions

$\oplus$ charge in cyclic carbonium ions

Scheme I

The CPCP mechanism does not apply for the formation of the primary reaction product 3 -ethylpentane. However, when the fundamental principles of this mechanism are adopted to a model involving cyclobutylcarbonium ions, a pathway of the formation of 3ethylpentane can be deduced (scheme 1, route 2) though the question already raised by Weitkamp [3] remains unanswered, namely why the rate of formation of ethylpentane is so extremely low. To explain this phenomenon Weitkamp suggested that methyl branched paraffins formed via the CPCP pathway may undergo in consecutive rearrangements to ethylpentane according to the well-established route via hydride and alkyl shifts. However, the ethyl-branched isomer proved to be a primary product of n-heptane isomerization (Figs. 6, 8) which contradicts the proposed reaction route.

The formation of dimethylpentanes can be explained when the CPCP mechanism is applied in an analogous manner to consecutive reactions of mono-branched primary reaction products. In this case tertiary 2-methyl- and 3-methylhexylcarbenium ions are directly transformed by ring opening of the respective cyclic intermediates into secondary 2,2- and 3,3-dimethylpentylcarbenium ions, respectively, and tertiary 2,3-dimethylpentylcarbenium ions (scheme 1, routes 3). Ring opening to 2,3-dimethylcarbenium ions resulting directly in tertiary carbenium ions should be favored over the formation of gemdibranched products which is experimentally confirmed (Table 2). On the other hand, due to the higher stability of tertiary carbenium ions in comparison to secondary ones the initial cyclization step should be much less favored than in reactions which start from linear carbenium ions and result in mono-branched isomers. That may be the reason for the great 
deviation of the amounts of dibranched reaction products from the thermodynamic equilibrium (Table 2). Adhering to the CPCP mechanism, the formation of 2,4dimethylpentane can be only proceed via 2-methylhexylcarbenium ions in which the positive charge is positioned at the secondary C-atom next to the branch (scheme 1, 4a). This ion is energetically much less favored than the respective tertiary carbenium ion (scheme 1, 3a) and consequently it is present in correspondingly low concentration. Nevertheless, the yield of 2,4-dimethylpentane was found to be commensurable to those of the other dibranched isomers. It can be, therefore, concluded that the tendency of 2methylhexane towards skeletal rearrangement according to reaction route 3 and 4 (scheme 1) is detrimentally influenced to a similar degree by the high stability, i.e. reduced reactivity, of tertiary ions and/or the low concentration of secondary carbenium ions.

A mechanistic concept based on isomerization via corner protonated cycloalkanes with larger ring numbers, first raised but then dropped again by Weitkamp [3], was later discussed in detail and applied to the isomerization of long-chain paraffins by Martens and Jacobs [5]. As to n-heptane isomerization, the formation of mono- and dibranched isomers can be consistently explained by analogy provided the pathway via primary carbenium ions in an intermediate state after ring opening would not be absolutely forbidden. At present it must remain an open question to which extent potential reaction routes of intramolecular rearrangements are blocked at points where the formation of stable end products proceeds via an energetically unfavored primary carbenium ion. The probability for the existence of primary carbenium ion intermediates may be differently treated for such intramolecular rearrangements and for bimolecular reactions in which carbenium ions are involved as separate individual species, e.g. in cracking via ß-scission.

At low conversions the two methylhexanes are formed in practically equimolar amounts (Figs. 6, 8 and 10), i.e. in a ratio near the thermodynamic equilibrium distribution (3MC6/2-MC6 = 0.92). At higher conversions (longer contact times) the yields of the two methylhexanes deviate somewhat but more and more in favor of the 3-methylhexane. The reason for that phenomenon may be that exclusively or predominantly 2,4- and 2,2dimethylpentylcarbenium ions are involved in hydrocracking (vide infra) which originate only from the 2-methylhexyl ion.

The release of the final carbenium ions from the catalyst in form of the respective paraffin isomer is, naturally, the last step of the CPCP mechanism and related concepts. It may be that in this step the final paraffinic isomers are formed by hydride transfer from a reactant molecule to the carbenium ion, similar to the chain-propagating step in the classical crack mechanism (vide supra). In this case the role of the metallic component would be restricted to chain initiation via dehydrogenation of some reactant molecules to heptenes. More recently new concepts have been proposed for hydroisomerization of paraffins over hybrid catalysts which involve dissociative activation of $\mathrm{H}_{2}$ on the surface of the metallic component, spill-over and surface diffusion of hydrogen atoms into the zeolite and hydrogenation of carbenium ions to the respective paraffins, e.g. papers in Ref. 25.

\subsubsection{Mechanism of hydrocracking over boron-substituted BEA varieties}

According to the classical cracking mechanism C-C bond rupture occurs in carbenium ions in $\beta$ position relative to the charged atom. Formation of primary cations is postulated to be forbidden for energetic reasons. Thus, among the isomers formed from n-heptane by isomerization (section 3.3.1.) only 2,4- and 2,2-dimethylpentyl-carbenium ions undergo cracking. In analogy to the last reaction step in the isomerization mechanism (vide supra), the charged crack fragments may be released from the catalyst surface as paraffins after either hydrogenation by "spill-over" hydrogen or hydride transfer from paraffin molecules. Thus, the formation of propane and butanes in equimolar amounts (Table 2) clearly evidences cracking via the classical $\beta$-scission mechanism since $n$-butane, very low in 
concentration per se, was obviously formed in a consecutive reaction by isomerization of ibutane. Further, yield vs. contact time curves clearly show that both propane and i-butane originate from a dibranched isomer as products of a consecutive reaction.

A cracking pathway via fast dimerization of $\mathrm{C}_{7}$ to $\mathrm{C}_{14}$ and subsequent fragmentation was suggested by Fuentes and Gates [26] and later discussed in detail in Ref. 6. According to this mechanism pentanes and hexanes are also typical cracking products. Among the products with less than $7 \mathrm{C}$ atoms obtained in the present study over Al- and Al/Bcontaining BEA zeolites hexanes, n-pentane (if detectable at all) and methane are definitely and exclusively due to hydrogenolysis on metallic nickel (vide supra). Thus, the lack of $\mathrm{C}_{5}$ and excess $\mathrm{C}_{6}$ paraffins clearly evidences that cracking reactions via dimerization did not operate over Ni-exchanged and reduced BEA zeolites. Further, no products with a carbon number exceeding 7 were found which should be expected in at least small amounts, even when they undergo fast cracking. For the same reasons isomerization of n-heptane via dimerization cracking, discussed in detail in Ref. 7, can be excluded.

\section{Conclusions}

- Part of the incorporated boron occupies tetrahedral framework positions and gives rise to weak acid sites which are involved in, e.g., ion exchange of nickel, while residual sodium ions exclusively compensate strong acid sites associated with tetrahedral framework aluminum.

- The intrinsic acid strength of Brønsted acid sites (bridged hydroxyls) associated with framework aluminum was found to be invariant to the boron content of BEA zeolites.

- The acid strength of weak sites associated with framework boron seems to be increased by a synergetic effect of coexisting framework aluminum, at least at high $\mathrm{Al} / \mathrm{B}$ ratios. However, these sites of weak acidity are irrelevant to catalytic hydroconversion of alkanes.

- Hydrogenation and acid functions of nickel-exchanged BEA zeolites and, hence, the catalytic properties of these bifunctional catalysts in the hydroconversion of alkanes can be well balanced by incorporation of framework boron into BEA zeolites with appropriate aluminum contents and subsequent ion exchange with sodium aiming at partial elimination of acidity and appropriate nickel levels.

- In the hydroconversion of $\mathrm{n}$-heptane, appropriately prepared $\mathrm{Ni} / \mathrm{H}-\mathrm{BEA}$ zeolites exhibited at $533 \mathrm{~K}$ isomerization selectivities up to $90-95 \%$ at $60 \%$ conversion level and negligible hydrogenolysis (about $1 \%$ ).

- Differences in the apparent rate constants and activation energies in the hydroisomerization of n-heptane to methylhexanes over boron free and boron containing BEA zeolites were ascribed primarily to composition dependent adsorption properties manifesting themselves in different isosteric adsorption heats.

Acknowledgment. The authors thank the financial support of the National Office for Research and Technology (NKTH, GVOP project No. 3.1.1. 2004-05-0505/3) and the Hungarian Research Fund (OTKA project No. K 68537).

\section{References}

[1] J. Weitkamp, Am. Chem. Soc. Symp.Ser., Vol.20 (1975) 1.

[2] J. Weitkamp, H. Farag, Acta Univ. Szegediensis, Acta Phys. Chem. 24 (1978) 327.

[3] J. Weitkamp, Ind. Eng. Chem. Prod. Res. Dev. 21 (1982) 550.

[4] M. Steijns, G. Froment, P.A. Jacobs, J. Uytterhoeven, J. Weitkamp, Ind. Eng. Chem. Prod. Res. Dev. 20 (1981) 654. 
[5] J.A. Martens, P.A. Jacobs, J. Catal. 124 (1990) 357.

[6] E. Blomsma, J.A. Martens, P.A. Jacobs, J. Catal. 155 (1995) 141.

[7] E. Blomsma, J.A. Martens, P.A. Jacobs, J. Catal. 159 (1996) 323.

[8] I. Eswaramoorthi, V. Sundaramurthy, N. Lingappan, Micropor. Mesopor. Mater., 71 (2004) 109.

[9] G. Kinger, D. Majda, H. Vinek, Appl. Catal. A, 225 (2002) 301.

[10] J.A. Wang, X.L. Zhou, L.F. Chen, L.E. Norena, G.X. Yu, C.L. Li., J. Mol. Catal. A: Chem., 299 (2009) 68.

[11] A. Chica, A. Corma, J. Catal. 187 (1999) 167.

[12] K.J. Chao, H.C. Wu, L. Leu, Appl. Catal. A, 143 (1996) 223.

[13] K.J. Chao, C.C. Lin, C.H. Lin, H.C. Wu, C.W. Tseng, S.H. Chen, 203 (2000) 211.

[14] P. Raybaud, A. Patrigeon, H. Toulhoat, J. Catal. 197 (2001) 98.

[15] G. Kinger, A. Lugstein, R. Swagera, M. Ebel, A. Jentys, H. Vinek, Micropor. Mesopor. Mater. 39 (2000) 307.

[16] G. Kinger, H. Vinek, Appl. Catal. A 218 (2001) 139.

[17] I. Eswaramoorthi, A. Geetha Bhavani, N. Lingappan, Appl.Catal. A 253 (2003) 469.

[18] P. Liu, J. Wang, X. Zhang, R. Wei, X. Ren, Chem. Eng. J. 148 (2009) 184.

[19] R.M. Mihályi, G. Pál-Borbély, H. K. Beyer, Á. Szegedi, T.I. Korányi, Micropor. Mesopor. Mater. 98 (2007) 132.

[20] H.G. Karge, W. Niessen, Catal. Today 8 (1991) 451.

[21] A. Zecchina, C.O. Areán, Chem. Soc. Rev. 25 (1996) 187.

[22] H. Knözinger, S. Huber, J. Chem. Soc., Faraday Trans. 94 (15) (1998) 2047.

[21] M.D. Romero, A. de Lucas, J.A. Calles, A. Rodriguez, Appl. Catal. A 146 (1996) 425.

[22] J.F. Denayer, W. Souverijns, P.A. Jacobs, J.A. Martens, G.V. Baron, J. Phys. Chem. B103 (1998) 4588.

[25] Spillover and Mobility of Species on Solid Surfaces, Eds.: A. Guerrero-Ruiz and I. Rodriques-Ramos, Stud. Surf. Sci. Catal. 138 (2001).

[26] G.A. Fuentes, B.C. Gates, J. Catal. 76 (1982) 440. 